\title{
'Ace of Hearts' and 'Little Woody' Redbuds
}

\author{
Paul R. Fantz
}

Department of Horticultural Science, Box 7609, North Carolina State University, Raleigh, NC 27695-7609

\author{
Paul Woody \\ 1821 Indian Trail, Morganton, NC 28655
}

Additional index words. Leguminosae, Fabaceae, Cercis, ornamentals

The eastern redbud (Cercis canadensis L.) (Fabaceae Lindl. or Leguminosae Adans.) is one of the first trees to bloom in late winter to early spring. The heart-shaped leaves add to summer's interest, and redbud is a good substitute for dogwood (Bridwell, 2003). Flowers are reddish-purple in bud, opening to a purplish-pink before leaves appear. Plants are effective in groupings, shrub borders, or as a single specimen for full sun to light shade. Redbuds are adaptable to a range of soil $\mathrm{pHs}$, and reach heights of 6 to $10 \mathrm{~m}$ with leaves 8 to $13 \mathrm{~cm}$ long and broad (Dirr, 1998). Several cultivars are popular in the trade. 'Forest Pansy' has small reddish-purple leaves. 'Covey' (PP 10,328) and 'Traveller' (PP 8,640) are dwarfs with a weeping growth form. 'Dwarf White' is a small upright tree, 3 to $4 \mathrm{~m}$ tall with white flowers. Two new cultivars described in this paper-'Ace of Hearts' and 'Little Woody' - are selections patented recently by Paul Woody, and exhibit upright, compact dwarf habits with small green leaves.

\section{Origin}

Paul Woody purchased 300 to 400 eastern redbud seedlings in 1997 from Ralph Edward's Nursery (North Carolina), subsequently purchased by Morganton Nursery (Morganton, N.C.). Seedlings ranged from 18 to 24 inches $(45$ to $60 \mathrm{~cm}$ ) in height and grew to 8 to 10 feet $(3 \mathrm{~m})$ tall by 2000 . As trees were dug for resale, Woody discovered amongst these plants a dwarf, compact redbud with small leaves. This plant was saved for observation and named 'Little Woody' for its dwarf stature and discoverer, Paul Woody. A short time later, Paul Woody encountered a second dwarf, compact redbud with smaller leaves, but different in growth form and leaf texture. Likewise, this second plant was saved for observation. It was named 'Ace of Hearts' for its semiglossy, small, heart-shaped leaves. In August 2000, Woody arranged for Don Shadow of Shadow Nursery Inc. (Winchester, Tenn.) to propagate both cultivars, to build up stock plants, and to evaluate character uniformity and stability over

Received for publication 31 May 2005. Accepted for publication 19Aug. 2005. The use of nursery and trade names in this publication does not imply endorsement by the North Carolina Agricultural Research Service of the nursery or the products mentioned, nor criticism of similar ones not mentioned. several seasons. Each selection was propagated by chip budding on $C$. canadensis seedlings. Budding produced 2 to 3 plants in the second generation (August 2000), 50 to 70 plants in the third generation (August 2001), and 150 to 170 plants in the fourth generation (August 2002). Plants are 0.5 to $1.5 \mathrm{~m}$ tall depending on age, growing in full sun in field plots (Winchester, Tenn.) with a soil $\mathrm{pH}$ of 6.5 (USDA Hardiness Zone 7b, USDA, 1990). Plants have performed well, maintaining their shapes without pruning, and surviving temperatures of $-3^{\circ} \mathrm{F}$. Each plant exhibited the unique and distinct traits of its parent, demonstrating character stability over several generations

\section{Description}

Colors were designated by Woody using the Royal Horticultural Society Colour Chart (Royal Horticultural Society, 1995). Herbarium type vouchers collected by the authors will be deposited at North Carolina State University (NCSC) Herbarium, Raleigh, with a duplicate set of vouchers to be sent to the National Arboretum (NA), Washington, D.C. Figures are the photos used in the patent applications.

'Ace of Hearts'. 'Ace of Hearts' is a new distinct cultivar of eastern redbud distinguished by its dwarf, compact habit, dome-shaped canopy, and small, shiny, heart-shaped leaves lacking the reddish-purple coloration. The original plant ( 8 years old) is a compact, multi-stemmed deciduous tree, $4 \mathrm{~m}$ tall and $5 \mathrm{~m}$ wide, with a dense, broad dome-shaped, about $5 \mathrm{~m}$ wide crown after 8 years of field growth in Burke County, N.C. (Fig. 1a). Bark is grayish (RHS 197B). Young branches are slender, weakly flexuous, 2 to $4 \mathrm{~mm}$ in diameter, greenish (RHS 146B-C) becoming dark gray-brown to grayish-brown (199A,200B-C) with age. Leaves are broad ovate-cordate, 4 to $6.5 \mathrm{~cm}$ long and 4 to $6.3 \mathrm{~cm}$ wide (Fig. $1 \mathrm{~b}$ ). The adaxial (upper) surface is dark green (RHS 132A, 136A, and 139A), smooth-textured and somewhat shiny, whereas the abaxial (lower) surface is pale with conspicuously reticulate veinlets observable when viewed at $7 \times$ magnification. Petioles are slender, 2 to $2.5 \mathrm{~cm}$ long, 1 to $1.5 \mathrm{~mm}$ diameter, yellowish-green (RHS 143C,144B), becoming reddish-tinged (RHS 178A) adaxially when exposed to sun. Inflorescences appear before the leaves bearing clusters of 4 to 8 reddish-purple (RHS 61A) buds (Fig. $1 \mathrm{c}-\mathrm{d}$ ). Flowers are papilionaceous
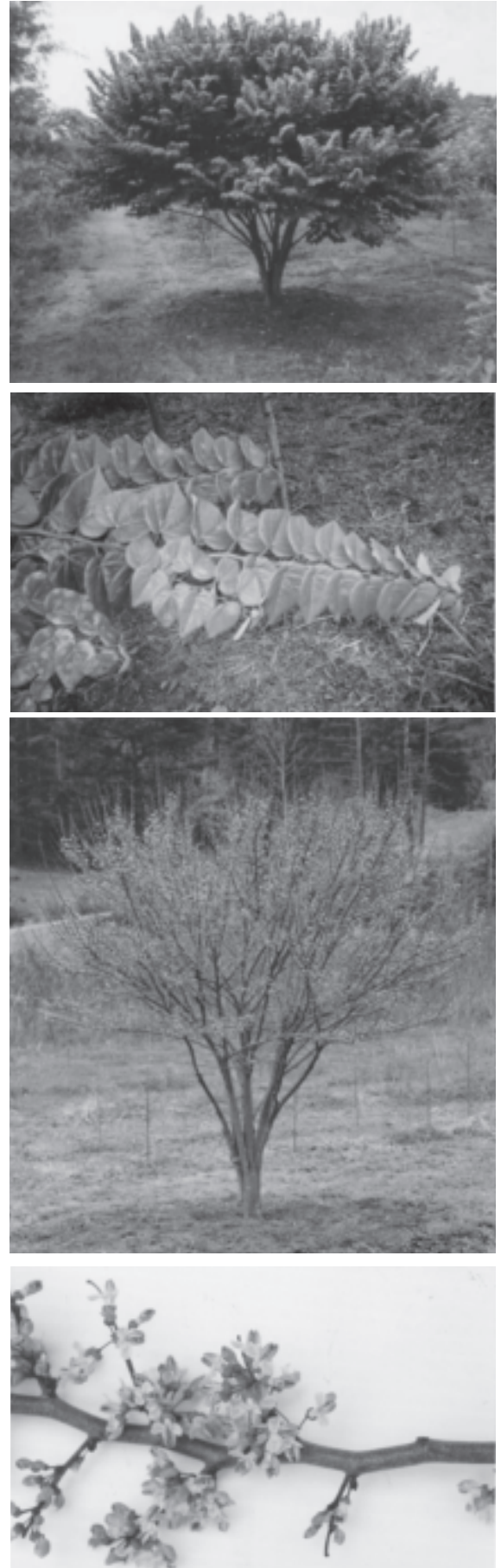

Fig. 1. 'Ace of Hearts' redbud (from the top): summer habit, dwarf tree with dome-shaped canopy; shiny, heart-shaped leaves; spring habit with flowers; a flowering branch.

(pea-like), light violet (RHS 82A-B), and borne on 4 to $5 \mathrm{~mm}$ long pedicels. The calyx is reddish-purple (RHS 71B-C). Fruit, while rare, is about $60 \mathrm{~mm}$ long and $14 \mathrm{~mm}$ wide, blackish-brown (RHS 200B-C), borne on 12-mm-long pedicels. HOLOTYPE: Fantz \& Woody 7401 (foliage). Paratypes: Fantz \& Woody 7290 (flowers) and Fantz \& Woody 7265 (buds).

'Little Woody'. 'Little Woody' is a new distinct cultivar of eastern redbud distinguished by its dwarf habit, vase-shaped growth form, and bullate-rugose, small, heart-shaped leaves. The original plant ( 8 years old $)$ is a compact, multistemmed, deciduous tree, $3.3 \mathrm{~m}$ tall with 

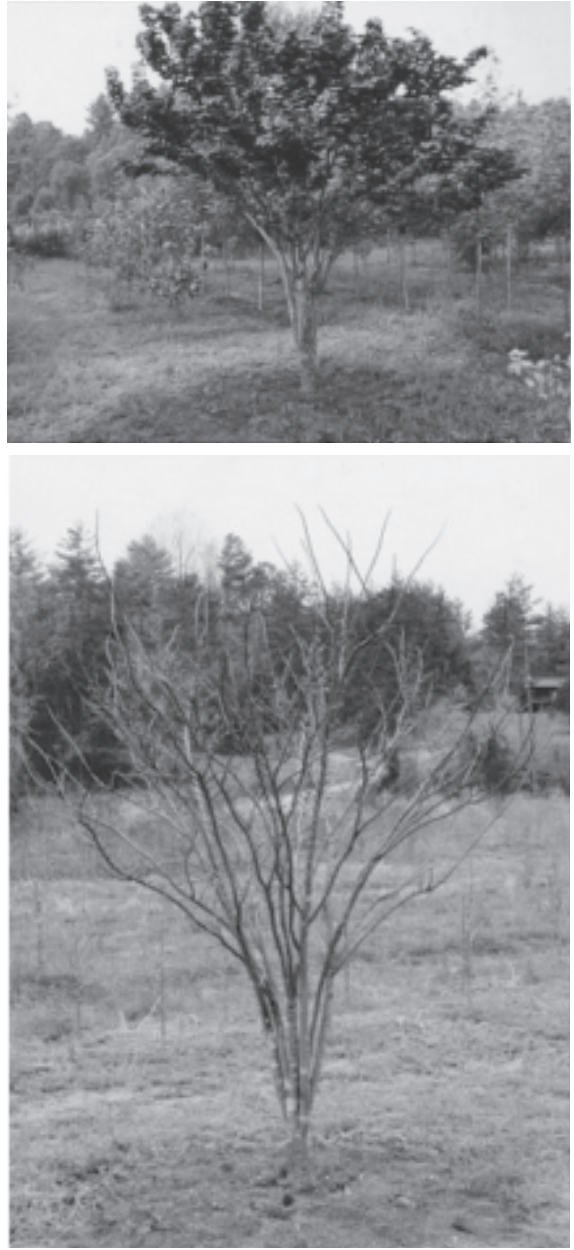

a vase-shaped growth form, the crown ascending-spreading to $3 \mathrm{~m}$ wide after 8 years of field growth in Burke County (Fig. 2a). Bark is grayish (RHS 197A). In the crown, the major limbs form conspicuous herringbone patterns, the pins spreading to suberect, forming a narrow to broad V-shaped pattern along the branch. Young branches are slender, 3 to $6 \mathrm{~mm}$ diameter,
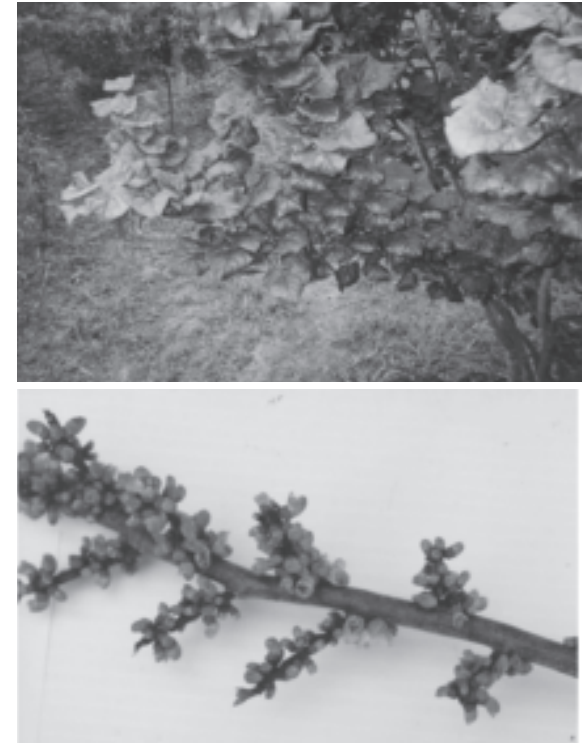

Fig. 2. 'Little Woody' redbud (clockwise from the top right): summer habit; dwarf tree with vaseshaped canopy, bullate-rugose, heart-shaped leaves; a flowering branch; spring habit with flowers.

greenish (RHS 146A, and 147B) becoming dark gray-brown to brown (RHS 201A) with age. Leaves are broadly ovate-cordate, 4 to 6 $\mathrm{cm}$ long and 4 to $7 \mathrm{~cm}$ wide, entire and slightly turned downward at the margin (Fig. 2b). The adaxial (upper) surface dark green (RHS 132A), bullate-rugose, whereas the abaxial (lower) surface is pale with conspicuously reticulate veinlets prominent when viewed at $7 \times$ magnification. Petioles are slender, 2 to $2.6 \mathrm{~cm}$ long, yellowish-green (RHS 144b and $145 \mathrm{~A}$ ), becoming reddish-tinged (RHS 178B) adaxially when exposed to. Inflorescences appear before the leaves bearing clusters of 2 to 7 reddish-purple (RHS 61A) buds (Fig. 2 $\mathrm{c}-\mathrm{d})$. Flowers are papilionaceous (pea-like), purplish (RHS 81B-C), and borne on 4 to 6 $\mathrm{mm}$ long pedicels. The calyx is reddish-purple
(RHS 71B-C). HOLOTYPE: Fantz \& Woody 7402 (foliage). Paratypes: Fantz \& Woody 7291 (flowers) and Fantz \& Woody 7266 (buds).

Observations. The buds of both cultivars swell in late March in Burke County. The calyx is reddish-purple and petals exhibit violet pigmentation that lightens as flowers open in early to mid April. Fruit were rare in each cultivar in 2003, whereas other trees grown from seedlings purchased in $1997 \mathrm{had}$ numerous fruit.

\section{Culture}

First generation plants are about $0.5 \mathrm{~m}$ tall to $1.5 \mathrm{~m}$ tall after 4 years. 'Little Woody' was slightly shorter than 'Ace of Hearts'. Other redbud plants from the same seed lot required selective pruning to obtain a desirable shaped plant for the landscape. Neither 'Ace of Hearts' nor 'Little Woody required pruning to obtain a desirable shape.

\section{Availability}

'Ace of Hearts' received a U.S. Patent number, which can be located using the application publication number (Pub. No. US2005-0138705-PI) or the USPTO search engine. 'Little Woody' received U.S. Patent No. PP 15,854 . Information on the availability of these cultivars can be obtained from Paul Woody.

\section{Literature Cited}

Bidwell, F.M. 2003. Landscape plants: Their identification, culture and use, p. 370. 2nd ed. Delmar, Albany, N.Y.

Dirr, M.A. 1998. Manual of woody landscape plants, p. 208-211. 5th ed. Stipes Publ. Co., Champaign, Ill.

Royal Horticultural Society. 1995. Royal Horticultural Society colour chart. Royal Hort. Soc., London.

U.S. Department of Agriculture. 1990. U.S. Department of Agriculture plant hardiness zone map. USDA Misc. Publ. 1475. 